http://jmscr.igmpublication.org/home/ ISSN (e)-2347-176x ISSN (p) 2455-0450

crossref DOI: https://dx.doi.org/10.18535/jmscr/v7i10.60

Journal Of Medical Science And Clinical Research

\title{
A Clinical Study of Chronic Cervical Lymphandenopathy in Government Medical College \& General Hospital (RIMS), Kadapa
}

\author{
Authors \\ Dr M. Ramachandra', Dr K.V. Vigneswar Rao², Dr V. Madhu Sudhan³, \\ Dr N. Prahalada Reddy ${ }^{4}$, Dr G. Bhaswanth Kumar Reddy, \\ Dr B. Ravi Theja ${ }^{6}$, Dr B. Hari Charan ${ }^{7}$ \\ ${ }^{1,2}$ Associate Professor, GMC \& GH, Kadapa \\ ${ }^{3}$ Senior Resident, GMC \& GH, Kadapa \\ ${ }^{4,5,6,7}$ Post Graduate, GMC \& GH, Kadapa
}

\begin{abstract}
Background: Ever since the documentation of functions of lymph nodes, the diseases of lymph nodes are understood in a better way. Varied number of disorders, ranging from trivial inflammatory conditions to serious malignant conditions affect lymph nodes. Cervical lymphadenopathy also forms the commonest cause of neck swellings. Cervical lymphadenopathy is the commonest region for specific lymphadenopathy. With this background, we have conducted a study on cervical lymphadenopathy in our institute to find out the various causes of cervical lymphadenopathy in our area.

Methods: The present study is a prospective, observational study conducted on fifty patients who attended to Government General Hospital/RIMS, Kadapa during a period of 2 years from January 2016 to December 2017. All the patient who presented with cervical lymphadenopathy were included in the study. A detailed history of the symptoms, thorough clinical examination and investigations were done, which were analyzed.

Results: Benign lymphadenopathy was the commonest cause of cervical lymphadenopathy accounting for $78 \%$ of all the cases. Tuberculous lymphadenitis was commonest cause of benign cervical lymphadenopathy accounting for $48 \%$ of benign causes and $38 \%$ of total cases. Primary tumours of lymph nodes constituted $14 \%$ and metastatic lymphadenopathy was the cause in $8 \%$ of the total cases.

Conclusion: Tuberculosis continues to be the commonest cause of cervical lymphadenopathy in our setup, the common age of presentation being in 2 nd and $3 r d$ decades. Secondaries in the neck occur in elderly age group. Provisional diagnosis of tubercular adenitis did not closely correlate with histopathological diagnosis. Clinical diagnosis of secondaries neck was closely associated with fine needle aspiration cytology (FNAC) report. FNAC is safe, quick and cost-effective procedure and has high patient acceptance. It is a good screening procedure for tuberculous lymphadenitis and secondaries of the neck.

Keywords: Cervical Lymphadenopathy FNAC, Secondaries of Neck, Histopathology.
\end{abstract}

\section{Background}

Ever since the documentation of functions of lymph nodes, the diseases of lymph nodes are understood in a better way. Varied number of disorders, ranging from trivial inflammatory conditions to serious malignant conditions affect 
lymph nodes. Cervical lymphadenopathy is the enlargement of neck lymph nodes. Of all the lymph node groups, cervical group is the most commonly involved for any diseases, for that matter which affects lymph nodes. They drain the upper respiratory tract and alimentary tract. These two epithelial layers are prone for repeated infections as well as fast multiplying epithelial sites are prone for infection.

As the causes of cervical lymphadenopathy range from benign inflammatory condition to malignancy, identifying the underlying cause in a given patient is of utmost importance for the treatment of the same. With this background, we have conducted a study on cervical lymphadenopathy in our institute to find out the various causes of cervical lymphadenopathy in our area. The present study aimed at understanding the incidence of various diseases, their age and sex pattern, common group of lymph nodes involved, correlation between clinical diagnosis and FNAC.

\section{Methods}

The present study is a prospective, observational study conducted on fifty patients with cervical lymphadenopathy who attended to Government General Hospital / RIMS, Kadapa to find out the various causes of cervical lymphadenopathy during a period of 2 years from January 2016 to December 2017.

\section{Inclusion Criteria}

- Lymphadenopathy of more than 4 weeks duration either with isolated or generalized lymphadenopathy.

- Age more than 15 years.

\section{Exclusion Criteria}

- Lymphadenopathy of less than 4 weeks duration.

- Lymph nodes of size less than $1 \mathrm{~cm}$.

- Age less than 15 years.

A detailed history of patients was taken. This was followed by thorough general, local and systemic examination. Routine biochemical investigations like complete blood picture (CBP), renal function tests (RFT), liver function tests (LFT) and serological tests for human immunodeficiency virus (HIV), hepatitis B surface antigen ( $\mathrm{HbsAg}$ ) were done. FNAC was done in all patients.

\section{Results}

Fifty cases of cervical lymphadenopathy were studied in detail for a period of 2 years and the different causes for 50 cases are tabulated in chart I. The age and sex distribution, the duration of symptoms, associated symptoms for various causes, group of lymph nodes involved, side of the neck involved, correlation of provisional diagnosis with final diagnosis (HPE), and correlation of FNAC with histopathological diagnosis are all tabulated in different tables and charts.

Following are the results obtained.

\section{Causes}

Benign lymphadenopathy was commonest cause of cervical lymphadenopathy forming $78 \%$, out of which tuberculosis lymphadenitis was the commonest cause accounting for $38 \%$. Primary tumors of lymph nodes constituted $14 \%$. Metastatic lymphadenopathy constituted for $08 \%$.

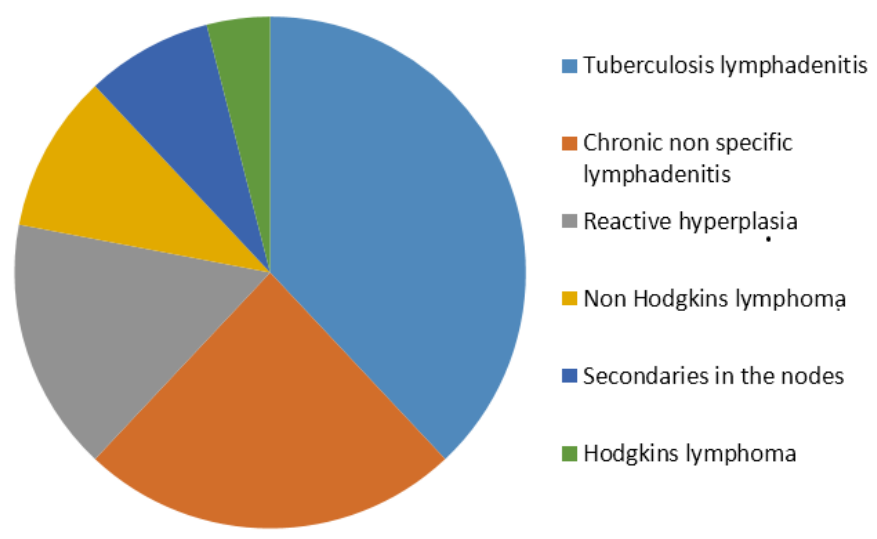

Chart -1: Causes of Cervical Lymphadenopathy

\section{Age Distribution}

Cervical lymphadenopathy was more common in $2^{\text {nd }}$ and $3^{\text {rd }}$ decades accounting for $54 \%$ and least common is $7^{\text {th }} \& 8^{\text {th }}$ decade accounting for $10 \%$. Malignancy was more common after 5th decade. 


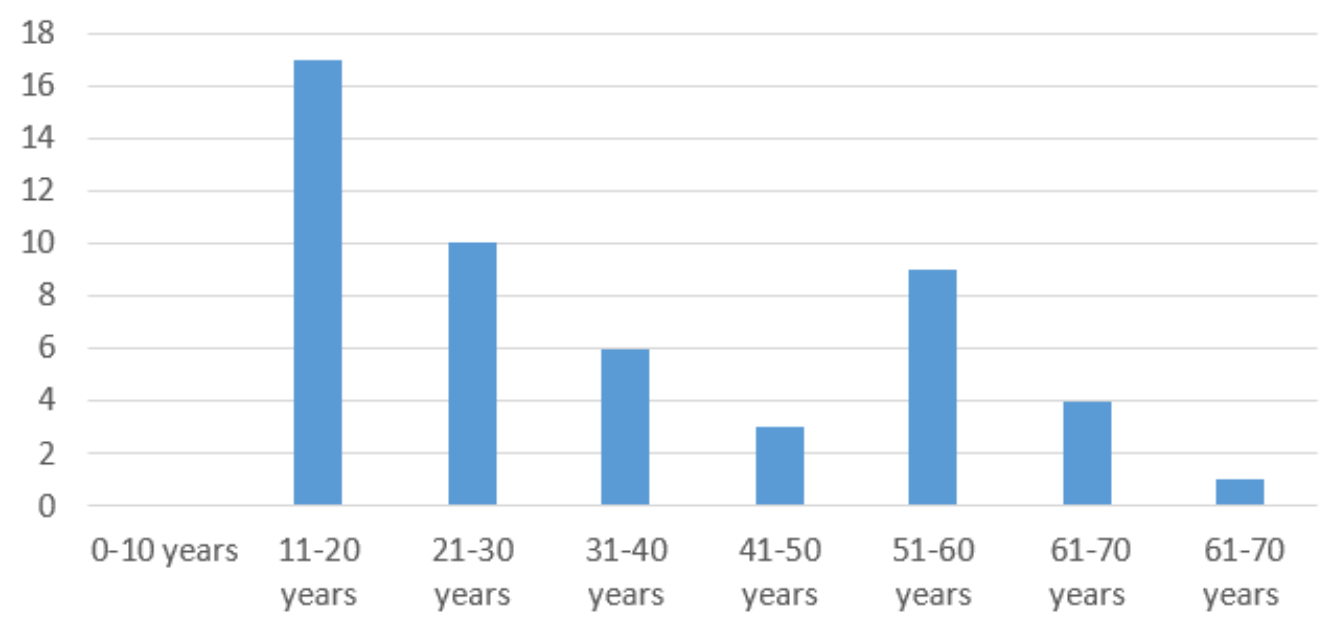

- Series 1

Chart - 2: Age Distribution of Cervical Lymphadenopathy

\section{Sex Distribution}

Cervical lymphadenopathy was more common in males accounting $60 \%$ of the total cases with females constituting only $40 \%$. Benign conditions were more common in females, especially $\mathrm{TB}$ lymphadenitis. Malignant conditions were more common in males.

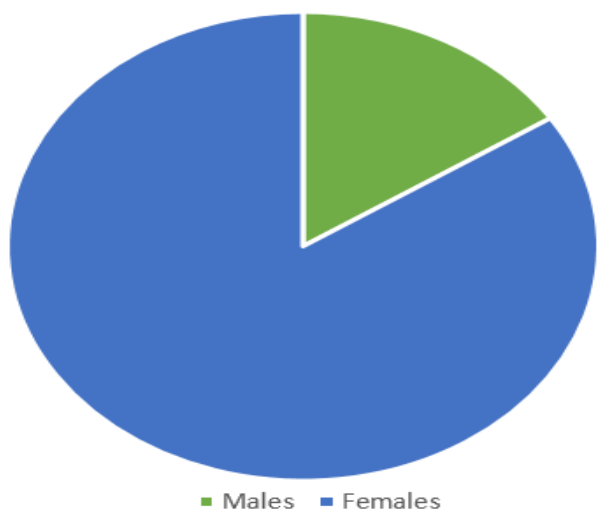

Chart - 3: Sex Distribution of Cervical Lymphadenopathy

\section{Side of the Neck Involved}

In our study conducted on 50 patients, right side of the neck was involved in 26 cases accounting for $52 \%$ and left side was involved in 17 cases accounting for $34 \%$. Bilateral cervical lymphadenopathy was observed in 7 patients in our study. Other groups of lymph nodes were involved in one patient of Hodgkin's Lymphoma and other patient of Non-Hodgkin's Lymphoma.

Table-1: Side of the Neck and Other Group of Lymph Nodes of Various Diseases

\begin{tabular}{|l|c|c|c|c|}
\hline Disease & Right Side & Left Side & Bilateral & Other group \\
\hline TB Lymphadenitis & 12 & 04 & 03 & - \\
\hline Chronic Non-Specific Lymphadenitis & 07 & 05 & 00 & - \\
\hline Reactive Hyperplasia & 03 & 05 & 00 & - \\
\hline Hodgkin's Lymphoma & 01 & 00 & 01 & 01 \\
\hline Non-Hodgkin's Lymphoma & 01 & 01 & 03 & 01 \\
\hline Secondaries & 02 & 02 & 00 & - \\
\hline Total & $\mathbf{2 6}$ & $\mathbf{1 7}$ & $\mathbf{0 7}$ & $\mathbf{0 2}$ \\
\hline
\end{tabular}


Involvement of Various Groups of Lymph Nodes in Various Diseases

Table-2: Involvement of Various Groups of Lymph Nodes in Various Diseases

\begin{tabular}{|l|c|c|c|c|c|}
\hline \multirow{2}{*}{ Disease } & \multicolumn{5}{|c|}{ Sites of Lymph Node Groups } \\
\cline { 2 - 6 } & $\begin{array}{c}\text { Sub } \\
\text { Mandibular }\end{array}$ & $\begin{array}{c}\text { Jugulo } \\
\text { Digastric }\end{array}$ & Jagulo Omohyoid & Supra Clavicular & Multiple Nodes \\
\hline TB Lymphadenitis & 03 & 13 & - & - & 03 \\
\hline Chronic non-Specific Lymphadenitis & 09 & 01 & - & - & 02 \\
\hline Reactive Hyperplasia & 03 & 03 & - & - & 02 \\
\hline Hodgkin's Lymphoma & - & - & 01 & - & 01 \\
\hline Non-Hodgkin Lymphoma & - & - & 01 & - & 04 \\
\hline Secondaries & - & - & 01 & 01 & 02 \\
\hline Total & $\mathbf{1 5}$ & $\mathbf{1 7}$ & $\mathbf{0 3}$ & $\mathbf{0 1}$ & $\mathbf{1 4}$ \\
\hline
\end{tabular}

In our study, Sub mandibular and Jugulodigastric lymph node were involved in $64 \%$ of pts, multiple nodes were involved in $28 \%$ of patients and Jugulo omohyoid was involved in just $06 \%$. In TB adenitis patients $69 \%$ of Jugulodigastric lymph nodes were involved. Jugulo-omohyoid was involved mostly in neoplastic diseases of lymph nodes. In chronic nonspecific lymphadenopathy submandibular was involved in $75 \%$ of pts.

\section{Correlation between Provisional Clinical Diagnosis and Final Diagnosis (Histopathological Diagnosis)}

Table-3: Correlation between Provisional Clinical Diagnosis and Final Diagnosis (Histopathological Diagnosis)

\begin{tabular}{|l|c|c|c|c|c|c|c|c|}
\hline \multirow{2}{*}{ Disease } & & \multicolumn{6}{c|}{ HPE } \\
\cline { 2 - 10 } & NO. & $\%$ & TB & $\begin{array}{l}\text { Chronic } \\
\text { Non-Sp. } \\
\text { Adenitis }\end{array}$ & $\begin{array}{c}\text { Reactive } \\
\text { Hyper plasia }\end{array}$ & Hodgkin's & NHL & Secondaries \\
\hline TB Lymphadenitis & 25 & 50 & 16 & 04 & 03 & - & 02 & - \\
\hline $\begin{array}{l}\text { Chronic Non-Specific } \\
\text { Lymphadenitis }\end{array}$ & 14 & 28 & 03 & 07 & 04 & - & - & - \\
\hline Lymphoma & 07 & 14 & - & 01 & 01 & 02 & 03 & - \\
\hline Secondaries & 04 & 08 & - & - & - & - & - & 04 \\
\hline Total & 50 & 100 & 19 & 12 & 08 & 02 & 05 & 04 \\
\hline
\end{tabular}

In our study, $50 \%$ of the total cases were provisionally diagnosed as tuberculosis lymphadenitis, out of which HPE proved only $32 \%$ cases. $28 \%$ of total case were diagnosed as chronic nonspecific lymphadenitis out of which
HPE proved $14 \%$ of cases. $14 \%$ of total cases were diagnosed as lymphomas out of which HPE proved $10 \%$ of cases. $08 \%$ of total cases were diagnosed as secondary lymphadenopathy out of which HPE proved $08 \%$ of total cases.

\section{Correlation of FNAC of the Various Diseases}

Table-4: Correlation of FNAC of the Various Diseases

\begin{tabular}{|l|c|c|c|c|c|c|c|}
\hline \multirow{2}{*}{ Disease } & \multicolumn{5}{|c|}{ FNAC } \\
\cline { 2 - 8 } & NO. & TB & $\begin{array}{c}\text { Chronic Non-Sp. } \\
\text { Adenitis }\end{array}$ & $\begin{array}{c}\text { Reactive } \\
\text { Hyper Plasia }\end{array}$ & Hodgkin's & NHL & Secondaries \\
\hline TB Lymphadenitis & 19 & 16 & 03 & - & - & - & - \\
\hline Chronic Non-Specific Lymphadenitis & 12 & - & 11 & 01 & - & - & - \\
\hline Reactive Hyperplasia & 08 & - & 06 & 02 & - & - & - \\
\hline Hodgkin's Lymphoma & 02 & 01 & - & 01 & - & - & - \\
\hline Non-Hodgkin Lymphoma & 05 & - & 01 & 02 & - & 02 & - \\
\hline Secondaries & 04 & - & - & - & - & - & 04 \\
\hline Total & $\mathbf{5 0}$ & $\mathbf{1 7}$ & $\mathbf{2 1}$ & $\mathbf{0 6}$ & $\mathbf{0 0}$ & $\mathbf{0 2}$ & $\mathbf{0 4}$ \\
\hline
\end{tabular}


Correlation of FNAC vis - a - vis HPE for Various Diseases

In our study, TB adenitis was diagnosed FNAC in 17 cases, out which 16 were correctly diagnosed, hence one case false positive and 3 cases were false negative. Chronic nonspecific adenitis was diagnosed by FNAC is 21 cases out of which 11 cases were correctly diagnosed, hence there were 10 cases of false positive and one case of false negative. FNAC could diagnose 6 case of reactive hyperpiesia. Out of which only 2 cases were correctly diagnosed, hence there were 4 cases of false positive and 6 cases of false negative, FNAC could not diagnose, any case of Hodgkin's lymphoma. Non-Hodgkin's lymphoma was diagnosed by FNAC in 2 cases, thus there were 3 cases of false negative. No false positive.

Table-5: Showing Accuracy of FNAC for Various Diseases in Percentage

\begin{tabular}{|l|c|c|c|c|}
\hline Sl. No. & Diseases & HPE & FNAC & Accuracy (\%) \\
\hline 1. & TB Lymphadenitis & 19 & 16 & 84.2 \\
\hline 2. & Chronic Non-Specific Lymphadenitis & 12 & 11 & 91.6 \\
\hline 3. & Reactive Hyperplasia & 08 & 02 & 25 \\
\hline 4. & Hodgkin's Lymphoma & 02 & 00 & 00 \\
\hline 5. & Non-Hodgkin Lymphoma & 05 & 02 & 40 \\
\hline 6. & Secondary Lymphadenopathy & 04 & 04 & 100 \\
\hline 7. & Over all & 50 & 35 & 70 \\
\hline
\end{tabular}

\section{Discussion}

Fifty cases of cervical lymphadenopathy were studied in detail during the above-mentioned period prospectively in GGH/RIMS, Kadapa. Benign lymphadenopathy was commonest cause of cervical. it accounted for $78 \%$ of cases out of which TB adenitis was the commonest cause. Primary tumors of lymph nodes constituted 14\% and secondaries for $8 \%{ }^{(5)}$ Cervical lymphadenopathy was more common in $2^{\text {nd }}$ and $3^{\text {rd }}$ decades accounting for $52 \%$ and least common in $7^{\text {th }}$ and $8^{\text {th }}$ decade accounting for $2 \%$. Malignancy was more common after $5^{\text {th }}$ decade. Swelling is the common symptom for all patients. Fever was associated with $73.6 \%$ patients with TB lymphadenitis and cough is the less common symptom associated with only $10 \%$ patients. Loss of weight and appetite was associated with $75 \%$ patients of metastatic lymphadenopathy. ${ }^{(4)}$ It is found that $50 \%$ of total cases were provisionally diagnosed as TB lymphadenitis, out of which HPE proved only $32 \%$ cases. $28 \%$ of total cases were diagnosed as chronic nonspecific lymphadenitis.

Table-6: Comparison of most Common Etiology of CCL with Other Studies

\begin{tabular}{|l|c|c|c|c|c|c|c|c|}
\hline Study & Year & TbAdenitis (\%) & $\begin{array}{c}\text { CNSL } \\
(\boldsymbol{\%})\end{array}$ & $\begin{array}{c}\text { Reactive } \\
\text { Hyperplasia (\%) }\end{array}$ & $\begin{array}{c}\text { Hodgkin's } \\
(\boldsymbol{\%})\end{array}$ & $\begin{array}{c}\text { NHL } \\
(\boldsymbol{\%})\end{array}$ & $\begin{array}{c}\text { Secondary's } \\
(\boldsymbol{\%})\end{array}$ & Total \\
\hline Narang D et al., & 1990 & 52 & 10 & - & 8 & 7 & 23 & 60 \\
\hline Malkar Detal., & 1991 & 39 & 15 & - & 15 & - & 31 & 61 \\
\hline Vernekar & 1996 & 45 & 46.25 & - & - & - & 2.5 & 80 \\
\hline Present Study & 2018 & 38 & 24 & 16 & 04 & 10 & 08 & 50 \\
\hline
\end{tabular}

Comparing the age distribution of my study with other studies. According to Nanda et al study-16, tuberculosis adenitis occurred majority in $2^{\text {nd }}$ and $3^{\text {rd }}$ decade. ${ }^{(4)}$ According to Pamra S.P.P et al study in 1 majority of TB adenitis occurred in $2^{\text {nd }}$ and $3^{\text {rd }}$ decade, when majority of primary and secondary lymphadenopathy were common after $5^{\text {th }}$ decade. $^{(5)}$
Comparing the most common presenting symptoms, according to A. Singh and M. Singh et al., 1986 study Out of 10 cases studied, 35 cases had fever. Loss of weight and appetite were observed in 30 cases. ${ }^{(8)}$ According to Pandap et M.C, et al., 1987, 36 cases of TB adenitis, there was no evidence of active pulmonary $\mathrm{Tb}$ in any of the cases. 
Table-7: Correlation between FNAC and Clinical Diagnosis

\begin{tabular}{|l|c|c|c|c|c|c|}
\hline \multirow{3}{*}{ Diseases } & \multicolumn{7}{|c|}{ Series } \\
\cline { 2 - 7 } & \multicolumn{2}{|c|}{ Tripathy et al., 1985 } & \multicolumn{2}{c|}{ Narang, et al., 1990 } & Present Series-2018 \\
\cline { 2 - 7 } & P. D & F. D & P. D & F. D & P. D & F. D \\
\hline TB adenitis & 16 & 14 & 32 & 29 & 25 & 16 \\
\hline CNSL & 05 & 04 & 04 & 02 & 14 & 0 \\
\hline Lymphomas & 06 & 05 & 10 & 07 & 07 & 05 \\
\hline Secondary's & 09 & 09 & 14 & 14 & 04 & 04 \\
\hline P.D = Provisional diagnosis, F.D =Final diagnosis \\
\hline
\end{tabular}

\section{Conclusion}

Tuberculosis continues to be the commonest cause of cervical lymphadenopathy followed by chronic nonspecific lymphadenitis. The common age of presentation being in 2 nd and 3rd decade. ${ }^{(1)}$ Secondary's occur in elderly age group. Cervical lymphadenopathy secondary to tuberculosis is found to be more common injugulodigastric group of lymph nodes differing with malignancy which can occur in any other group. Provisional diagnosis of tubercular adenitis was not closely associated with histopathological diagnosis. Clinical diagnosis of secondary's neck was closely associated with FNAC.FNAC is safe, quick and cost-effective procedure and has high patient acceptance. ${ }^{(3)}$ It is a good screening procedure for TB adenitis and secondary's neck.

\section{References}

1. Ackerman's - Surgical pathology, 8th edition 1996.

2. Ahmad. I -Nonspecific reactive hyperplasia of cervical lymph nodes - a follow up - J-Pak. Med. Asiso. 1992 Oct,42(1Q), 237-8.

3. Anderson. J.R. - Text book of pathology, 8th ediiton, 1985.

4. Arora. B. and Arora D.R. - FNAC in diagnosing tuberculous lymphadenitis Ind. J. medicine.res (A), May 1990, 189-92.

5. Arora. V.K, Bedi. R.S. et ai - A clinico pathological study of superficial lymphadenopathy in northern India, ind. J. Tub, 1987, 34,189-91.

6. Bailey and Love - Short practice of surgery, 23rd edition, 2000.
7. Barbara. L. Steeletai - FNAC in the diagnosis of lymphadenopathy in 1103 patients - Acta cytol, 1995:39:1,76-81.

8. Barton. L.L. - Childhood cervical adenitis. J. Am. Fam. Phy, 1984 April, 29(4),163-6.

9. Boyd - Text book of pathology, 9th edition, 1990.

10. Carter. T.R, Feidman. RS. et al - FNAC in the diagnosis of lymphoma, Acta cytol, 1998, 32, 848-53.

11. Dandapet. M.C, Panda B Keta S-Diagnosis of tuberculous adenitis by FNAC, Ind. J.Tub. 1987, 34.139-42.

12. Das gupta. A, Ghosh. R.N. et al -FNAC of cervical lymphadenopathy with special reference to tuberculosis. J. lnd-Med. Asso, 1994Feb:92(2):44-6.

13. Das. D.K, Gupta. S.K. et al - FNAC of Hodgkin's disease and subtype, scope and limitaitons, Acta cytol, 1990, 34, 329-36.

14. Das. S. - A manual on clinical surgery, 4th edition, 1996,

15. Das. S.- A text of surgical short cases, 2nd edition, 1999.

16. Davidson - Text book of medicine, 18th edition, 1999

17. Deepjyothi. V et al - diagnosis of tubercular cervical lymphadenitis by FNAC, Microscopy and culture, Ind.J. Tub 1991:1,38,25-29

18. Edward. W. Saitz - Cervical lymphadenitis caused by atypica! mycobacteria -Paed.cii. of north America, 1981,28,4,823-39,

19. Farquharson's - Text book of operative surgery, 8th edition, 1995.

20. Fermont. D.C. - Malignant cervical Iymphadenopathy due to unknown 
primary - J. Clin. Radio!, 1980 May, 31(3), 355-8.

21. George Lumta - Tumours of lymphoid tissue, 1970.

22. Godwin. J.T.- Aspiration biopsy technique and application, Am. Ny. Acad. Sci, 1956, 63:1348-73.

23. Gray's - Text book of anatomy, 38th edition, 1995.

24. Greene. D.A.-localised cervical lymphadenoapthy induced by diphenyl hydantoin sodium - Arch -Otolaryngol, 1975 July/ 101 (7),446-8.

25. Gupta. S.K. et al - Lymphnode aspiration biopsy in diagnosis of lymphoma, I.J.RM. Oct 1977: 231-37.

26. Guyton \& Hall - Text book of physiology, 9th edition, 1998,

27. Hamilton Bailey's - Physical signs in clinical surgery, 18th edition, 1997.

28. Harrison's pricipies of internal medicine, 14th edition, 1998.

29. Harrys L. loachim • b/mphnode biopsy, 1982.

30. Hooper. A.A.- Tuberculous peripheral lymphadenitis, BJS, 1972,59:No.5, 353-54.

31. James. E. Wright - Cervical lymphadenitis in childhood - Med. J. Aus - 1989, 150, 150-51.

32. Jatin, P. Shah et al - cervical lympanode metastasis - current problems in surgery, 1993, 30(3), 273-84.

33. Joseph. A. Linsk - Clinical aspiration cytology, 2nd edition, 1986.

34. Lau. S.K. et a! - Efficacy of FNAC in the diagnosis of tuberculous cervical lymphadenopathy - J. Laryngo, Otol, 1990, Jan.104(1), 24- 7.

35. Lee Mc. Gregor - Synopsis of surgical anatomy, 12th ediion, 1986.

36. Leopold. G. Koss Vol-2- Diagnostic cytology, 3rd edition, 1979.

37. Lonsdale D. - recurrent febriie cervical lymphadenoapthy treated with large doses of vitamin B1- Dev-Pharmacol-Thir, 1980, 1(4), 254-64.

38. Luqman.M and Jefery - FNAC of lympnodes, J.RM.A, 1980, 267-69.

39. Malakar. D et al-A clinical evalauton of FNAC in the diagnosis of lymphadenopathy, Ind. J.Tub, 1991,38,17-19.

40. Margaret. J. Evans et al - Atypical mycobacteria! lymphadenitis in childhood -A Ciinicopathologicai study of 17 cases. J. Cit. Path, 1998, 51,925-27,

41. Mohan Singh-incidence of Hodgkin's disease in lymphanode biopsy, J.1 nd.M.A, 1963;No.Q, 41, 432-39.

42. Na-DG, Lim. H.K. el ai - Differential diagnosis of cervical lymphadenoapthy usefulness of color doppler sonopgraphy AJR- AM.J-Roentgerol, 1997 May:168(5):1311-6.

43. Nanda. B.P. et al - peripheral lymphnode tuberculosis - a cornparision of various methods of management, Ind.J. Tub, 1986, 33,21-23.

44. Narang. R.K, Pradan.S. et al - Place of FNAC in diagnosing lymphadenopathy, Ind. J.Tub, 1990,31,29-31.

45. Nelson - Text book of paediatrics, 16th edition, 1999," •

46. O'Dowd. G.T. Frable et al - FNAC of benign lymphnode hyperplasia, Acta cytol, 1985, 29. 554-56.

47. Pamra.S.R\&Mathur.G.P.-Cervical lymphadenopathy, Ind.J,Tub, 1987，34, 96-100.

48. Patra. A.K, Nanda. B.K. et al - Diagnosis of iymphadenoapthy by FNAC, I.J.RM. 1983,26.273-76.

49. Peei.ALG - Peripheral tuberculous adenitis in the elderly, BJS, 1972, 59; NO.7, 56869.

50. Purohit. S.D, Guptha. M.L et al - A novel clinical scoring method for dignosing of tubercular cervical lymphadenitis, Ind. J. Tub, 1987, 34,22-24. 
51. Ramadan. H.H. et al - FNAC of head and neck and masses in children -Am. J. Otolaryngo, 1997 nov-dec, 18(6), 400-4.

52. Randall. C.F. - Recent advances and treatment of head and neck surgery-Recent advances in surgery - Taylor.1.NO.1 5, 1991,153-70.

53. Rao. R.S - Recent advances in management of cancers of head and heck recent advances in surgery - Roshanlal Guptha, Vol-5, 1996, 37-54,

54. Richard. S.Sne!! - Text book o! clinical anatomy, 5th edition, 1995.

55. Robbins - Pathological basis of disease. 5th edition, 1994,

56. Sabiston - Text book of surgery, 15th edtiion, 1997.

57. Sarda. A.K, Ball.S. et a! - FNAC as a priliminary diagnostic procedure for asymptomatic cervical lymphadenopathy 1988, Oct:86(4)-482-8

58. Schwartz's - Principle's of surgery, 6th editon, 1994.

59. Sen. S.K. - Tuberculous lymphadenitis. Ind. J. tub, 1955, 2, 137-40.

60. Shaha. A,. Webber. E et ai - FNAC in the diangosis of cervical lymphadenopathy, Am. J. Sur, 1986 Oct, 152(4) 420-3.

61. Singh. A, Singh. M. et al - role of FNAC in diagnosis of lymphadenopathy, Ind.J, Surgery. April 1986:21'132-37.

62. Singh. J.P, Chaturvedi. N.K et al - Role of FNAC in tuberculous lymphadenitis, Ind. J. Path. Micro. 1989. 32.2,101-4.

63. Singhai. S.L. \& Ghoo!y. A.M Tuberculosis of peripheral lymphnodes, Ind. J. Surgery, April 1963, 25 243-54. 